\title{
ESTUDIO CRÍTICO SOBRE EL NÚMERO DE TRIBUTARIOS EN CHIAPAS (1560-1817). UnA PROPUESTA METODOLÓGICA PARA LA HISTORIA DE LA POBLACIÓN
}

\author{
Tadashi Obara-Saeki
}

Resumen: El presente artículo tiene como propósito ofrecer, a través del análisis de la historia de la tasación del tributo en la provincia de Chiapas (1560-1817), conocimientos básicos sobre el número de tributarios, como una forma de acercarnos a la evolución de la población. El artículo revela la cambiante definición del tributario y la manera en la que se tasaba el tributo y en la que se contaban tributarios con el fin de hacer una propuesta metodológica para estudios históricos de la población.

Palabras clave: historia de la población, sistema tributario, tasación del tributo, padrón

Enviado a dictamen: 28 de junio de 2012

Aprobación: 26 de julio de 2012

Revisiones: 1

Mtro. Tadashi Obara-Saeki, maestro en Antropología Social, CIESAS-DF, profesor en la Universidad Femenina Showa (Tokio, Japón). Temas de especialización: historia colonial de Chiapas, historia de la población, el sistema tributario en el Chiapas colonial. Correo electrónico: tada06@gmail.com.
Abstract: This article intends to offer, through the analysis of the history of the assessment of the tribute in Chiapas (15601817), a basic knowledge on the number of tributaries as a way to approach the evolution of the population. The article reveals the changing definition of the tributary, the way in which the tribute was assessed and the way in which tributaries were counted in order to make a methodological proposal on historical studies of the population.

Keywords: population history, tributary system, assessment of tribute, census

\section{Introducción}

$1 \begin{aligned} & \text { lestudiar los tiempos en los que no se realizaban } \\ & \text { de manera sistemática censos de población, los } \\ & \text { historiadores tienen que buscar lo que pueden }\end{aligned}$ utilizar como fuentes para el estudio de la población. También tienen que hacer una interpretación crítica de esas fuentes, indagando con qué finalidad y bajo qué sistema administrativo fueron producidas esas fuentes. Para la investigación histórica de la población —igual que en otros campos de la historia-, la interpretación crítica de las fuentes es un primer paso.

En los estudios que han tratado la población de México y Guatemala en la época colonial, se 
pueden observar tres tipos de fuentes utilizadas: 1) registros de bautizos, matrimonios y entierros; 2) censos de población realizados con diversos fines y en diversas ocasiones desde mediados del siglo XVIII; y 3) documentos sobre el número de tributarios. Los estudios de "demografía histórica" que utilizan los registros de bautizos, matrimonios y entierros han logrado calcular, para periodos preestadísticos, los índices de nacimientos, matrimonios y defunciones, y han logrado analizar el movimiento de población de mediana y larga duración (Morin, 1973; Calvo, 1973; Lutz, 1982; Rabell, 1990; Pescador, 1992; Robichaux, 2001). Sin embargo, dado que se requiere de una enorme cantidad de tiempo y trabajo para sacar los datos de los libros parroquiales y analizarlos, es casi obligatorio limitar su objeto de estudio a una parroquia o una ciudad. En otros términos, no es un método adecuado o recomendable para un investigador a quien le interese estudiar una amplia región abarcar muchas parroquias o realizar la comparación de varias regiones relativamente extensas. Los estudios que han utilizado censos de población, llevados a cabo en un distrito civil o eclesiástico - corregimiento, alcaldía mayor, obispado, etcétera-, tienen la ventaja de poder trabajar la población de una amplia región en un momento determinado. Sin embargo, el periodo que pueden abarcar se limita a los tiempos posteriores a mediados del siglo XVIII. No se realizaron, pues, censos de población en el periodo comprendido entre el siglo XVI y la primera mitad del siglo XVIII (Cook y Borah, 1998: 58-60; Sánchez-Albornoz, 1994; Arias de Blois, 1994; Lutz, 1994). Este trabajo, dejando de lado estas fuentes arriba mencionadas, arroja luz sobre los documentos en los que se registró el número de tributarios. Dado que en casi todos los documentos se informa sobre el número de tributarios de cada pueblo, es relativamente fácil sacar y analizar los datos si utilizamos el número de tributarios como datos de población. Así se puede tratar tanto la población de los pueblos, como la de regiones relativamente amplias. Además, puesto que los documentos en los que se registró el número de tributarios datan del periodo comprendido entre la segunda mitad del siglo XVI y principios del XIX, éstos constituyen una importante fuente que complementa el periodo preestadístico, que va de la segunda mitad del siglo XVI a la primera del XVIII. Es cierto que los tributarios eran indios en principio y que el objeto de investigación se limita necesariamente a la población india. Pero eso no supone un gran problema cuando se estudian regiones o periodos en los que los indios constituían una gran mayoría. En virtud de estas características, se ha utilizado el número de tributarios como fuente demográfica en muchos estudios históricos sobre población (Borah y Cook, 1960; Cook y Borah, 1998; Gerhard, 1991: 21, 124; Carmack, 1981: 47-48; Lovell, 1990: 159; Lovell y Lutz, 2000: 11)

Sin embargo, a pesar de que los estudios históricos de la población han tratado de estimar la población india a partir del número de tributarios, rara vez se ha realizado una rigurosa crítica de fuentes sobre los documentos en los que se registró el número de tributarios. Por una parte, cada estudioso ha propuesto un factor de conversión para estimar el total de la población india y ha argumentado a partir del número de tributarios qué factor es el más adecuado o de qué manera se puede determinar un factor razonable. ${ }^{1}$ Por otra parte, con respecto al número de tributarios - los datos empíricos sobre los que se basan estos estudios-, los investigadores no se han preocupado por comprender las características del sistema administrativo que produjeron la documentación ni el procedimiento mediante el cual se elaboraron los documentos. En particular, para el distrito de la Audiencia de Guatemala - que corresponde a la mayor parte de la actual Centroamérica一, no se ha estudiado el sistema tributario con una perspectiva que abarque todo el periodo colonial, y los estudios históricos de población se han realizado sobre una base frágil o incluso errónea. Para el virreinato de la Nueva España, Cook y Borah realizaron un estudio 
sobre el sistema tributario ${ }^{2}$ y para distintos momentos del periodo colonial propusieron una estimación de la población a partir de los datos del número de tributarios (Cook y Borah, 1998). Sin embargo, ellos aprovecharon sus conocimientos sobre el sistema tributario para estimar el factor de conversión, pero no aclararon en profundidad el sistema administrativo que produjo la documentación sobre el número de tributarios.

Por lo tanto, con el fin de ofrecer una base sólida y proponer una nueva orientación sobre los estudios históricos de población, en este trabajo se muestra cómo se fijaba el número de tributarios y bajo qué sistema administrativo se produjo la documentación en la que se registraba. Como espacio de trabajo, tomamos la provincia de Chiapas del distrito de la Audiencia de Guatemala y recorremos el periodo comprendido entre 1560 y $1817 .^{3}$ Al estudiar detalladamente el caso de la provincia de Chiapas, tratamos de encontrar una pista para entender la historia del sistema tributario en el distrito de la Audiencia de Guatemala.

Para llevar a cabo esta tarea, dividimos este trabajo en tres partes. En la primera, mostramos quiénes eran tributarios: para ello, primero revisamos rápidamente el contexto histórico en el que se creó el sistema para tasar el tributo y en el que se empezó a contar el número de tributarios de cada pueblo; luego presentamos los cambios que se produjeron tanto en la definición del tributario como en la manera de calcular su número desde la segunda mitad del siglo XVI hasta principios del XIX. En la segunda parte señalamos cómo se fijaba el número de tributarios, explicamos con qué frecuencia se renovaba la tasación del tributo y describimos el procedimiento de la tasación, mostrando que el padrón de tributarios era la fuente original de todos los datos sobre el número de tributarios; luego, revisamos el procedimiento con el que se elaboraba el padrón de tributarios. En la tercera parte, analizamos los distintos elementos que aparecen en un padrón de tributarios, tomando como ejemplo el caso del padrón del pueblo de Chiapa elaborado en 1759 y, después, señalamos los cambios históricos que conocieron estos elementos en el periodo comprendido entre fines del siglo XVI y principios del siglo XIX. Al final, proponemos algunas líneas de investigación histórica de la población, que pueden plantearse a partir del conocimiento preciso, tanto de la tasación del tributo como del número de tributarios.

\section{¿Quiénes eran tributarios?}

\section{El número de tributarios como criterio de tasación del tributo}

En 1523, la Corona española expidió una ordenanza que obligaba a la tributación de los indios como reconocimiento de su señorío (Recopilación de leyes..., 1973, vol. 2, libro 6, título 5, ley l,f. 208r; Zavala, 1973: 44-45). Sin embargo, esto no quiere decir que en ese momento ya se hubiera establecido el sistema tributario que duraría hasta el fin de la dominación colonial. Fue en la década de 1550 cuando la tasación del tributo se reglamentó, y el número de tributarios se convirtió en su principal criterio. ¿Por qué y cuándo el gobierno español empezó a registrar el número de tributarios? A continuación mostramos en qué contexto histórico se produjo este fenómeno en la provincia de Chiapas.

En las tierras que formarían la provincia de Chiapas, la conquista española comenzó en 1524: una tropa de españoles partió de la villa del Espíritu Santo actualmente Coatzacoalcos- y conquistó el noroeste de Chiapas, pero se retiró sin haber fundado ninguna villa en las tierras exploradas dado que algunos pueblos de indios, a pesar de su inicial rendición, se alzaban y no se les podían someter fácilmente. Cuatro años más tarde, en 1528, dos huestes españolas, una enviada desde la ciudad de Guatemala bajo el mando de Pedro de Portocarrero, y la otra enviada desde México, dirigida por Diego de Mazariegos, llegaron a las tierras de Chiapas casi al mismo tiempo. Cada una fundó una villa de españoles en las tierras nuevamente conquistadas. 
Muy pronto, como resultado de un acuerdo político, los españoles que llegaron de Guatemala poco antes que los de México tuvieron que abandonar su villa recién fundada y elegir entre volver a Guatemala o incorporarse al grupo que llegó de la ciudad de México. Así, a pesar del conflicto entre los mismos españoles, ese año se estableció un gobierno español de la provincia de Chiapas con una sede definida (Lenkersdorf, 1993).

Para los indios que habitaban las tierras de Chiapas, el año de 1528 fue el momento clave ya que a partir de ese año se vieron obligados a tributar a sus nuevos amos, salvo algunos pueblos que, desde 1524, habían comenzado a tributar. Durante los primeros 15 años, no existió prácticamente ninguna reglamentación que rigiera el monto y el modo de la tributación, así que cada encomendero podía determinar, de acuerdo con los caciques y principales, las condiciones de la tributación - qué especies, cuánto y cada cuánto tiempo, etcétera- No resulta demasiado sorprendente que los indios hayan sido forzados a tributar un monto excesivo de metales preciosos y diversos productos, o bien hayan sido obligados a realizar trabajos pesados como una forma de tributación. ${ }^{4}$ En 1536, para poner fin a la ilimitada explotación de los encomenderos, la Corona española ordenó al obispo y al gobernador de Guatemala que tasasen el tributo de cada pueblo investigando el tamaño de la población y la calidad de las tierras. ${ }^{5}$ Este es el inicio de la tasación del tributo. En la provincia de Chiapas, esta orden fue llevada a cabo en 154l. Después del establecimiento de la Audiencia de Los Confines en 1543, las tasaciones bajo la autoridad de la Audiencia se renovaron dos veces más: en 1546 y en $1549 .{ }^{6}$

Sin embargo, en estas primeras tasaciones, aunque fuera obligación del juez que realizaba la tasación investigar la población y las tierras de cada pueblo, no existía ninguna regla concreta que definiera con qué criterio determinar el monto y los productos del tributo. Además, dado que los jueces a menudo realizaron la tasación del tributo sin haber visitado los pueblos (Ximénez, 1999: vol. 1, libro 2, cap. 58, p. 395;
Recopilación de leyes, vol. 2, libro 6, título 5, ley 27, f. 212v), la población y las tierras rara vez fueron investigadas verdaderamente. Así, en la década de 1550 la Corona llevó a cabo una reforma drástica de la tasación: introdujo un nuevo sistema conforme al cual se fijaban de antemano el monto y los productos que debía entregar cada tributario. Luego se procedió a contar los tributarios de cada pueblo y, finalmente, se fijaba el monto total de cada producto con el que el pueblo debía contribuir anualmente en función del número de tributarios. ${ }^{7}$ En virtud de dicha reforma, el número de tributarios de cada pueblo adquirió un importante significado en el sistema tributario y cada vez que se volvía a realizar la tasación del tributo se contaba de nuevo el número de tributarios. En la provincia de Chiapas, se renovaron las tasaciones del tributo conforme a este nuevo sistema hacia $1560 .^{8}$

\section{La definición de tributario y el número de tributarios}

Hemos visto el contexto en el que se introdujo un sistema regulado para tasar el tributo y que convirtió el número de tributarios en el principal criterio de tasación. Dijimos que en la provincia de Chiapas se comenzó a contar el número de tributarios hacia 1560, pero es de destacar que no todos los indios de la comunidad de un pueblo, hombres y mujeres, jóvenes y ancianos, se contaban como tributarios. ¿Cuáles, entonces, fueron los criterios por los que un indio se contaba como tributario? ¿Cómo se calculaba el número de tributarios? En las siguientes líneas aclaramos cómo fueron cambiando varias veces tanto la definición de tributario como la manera de calcular su número durante el periodo que va desde la década de 1560 hasta el fin de la dominación española.

\section{$1560-1570$}

Cuando se llevó a cabo la reforma de la tasación y se empezó a tasar el tributo en función del número de 
tributarios hacia 1560, un hombre casado, en principio, se contaba como un tributario. ${ }^{9}$ Se consideraba tributario un varón casado que habitualmente poseía casa, solar y milpa, lo que le permitía mantener una familia y pagar el tributo. Los solteros de ambos sexos y las viudas que no tenían dichos bienes se consideraban eximidos del tributo ya que no tenían recursos para mantenerse ni para pagar el tributo. Hemos encontrado alguna información sobre los viudos en esta década, pero es probable que quienes tenían casa y milpa se hayan contado como tributarios. ${ }^{10}$

\section{$1570-1616$}

En la provincia de Chiapas, durante el periodo comprendido entre 1570 y 1616 se contaban como tributarios no sólo los hombres casados, sino también los viudos de ambos sexos así como los varones solteros que no vivían bajo la potestad paterna. Dado que los viudos de ambos sexos y los hombres solteros no tenían pareja que les ayudara a pagar el tributo, se les obligaba a contribuir sólo con la mitad del tributo. ${ }^{11}$ Por ello, es probable que cada uno de ellos se haya contado como "medio tributario" al calcular el número de tributarios de un pueblo. ${ }^{12}$ Por otra parte, todo parece indicar que en este periodo las mujeres solteras habían estado eximidas de tributación. ${ }^{13}$

$1616-1635$

En la provincia de Chiapas, a partir de 1616 aproximadamente las mujeres solteras también fueron obligadas a tributar. Durante las dos décadas siguientes, se contaban los hombres casados como "tributarios enteros", los hombres viudos y solteros como "medios tributarios" y las mujeres viudas y solteras como tercios tributarios. Con tercios tributarios queremos decir que tres de éstos formaban un "tributario entero". La cuota que pagaban también difería entre estas tres categorías de tributarios: las mujeres viudas y solteras normalmente contribuían con la menor cantidad del tributo. ${ }^{14}$

En el periodo posterior a 1620 podemos observar otro cambio importante en la definición de tributario: al contar a un indio como tributario, antes se tenía en cuenta si éste tenía casa, solar y milpa, es decir, que les permitieran mantener a su familia; después, eso ya no importaba y a los indios se les obligaba a tributar a una edad determinada. En efecto, en los autos de tasación de los pueblos de la provincia de Chiapas realizados entre 1616 y 1618 se mandaba, por una parte, que tributasen los hombres entre 16 y 54 años, y las mujeres entre 16 y 49 años; por otra parte, se ponía una reserva a esta norma declarando que no debía cobrarse el tributo a los solteros y solteras que estuvieran bajo potestad paterna. ${ }^{15}$ Sin embargo, no podemos observar tal reserva en los autos de tasación realizados en los años posteriores a $1620 .{ }^{16}$ Según la Recopilación de Indias, dos veces, en 1578 y 1618, se expidió la disposición de que "los [solteros] que pasaren de 18 años de edad tributen hasta que cumplan 50" aunque estuvieran bajo la potestad paterna. ${ }^{17}$ En la provincia de Chiapas esta disposición parece haberse puesto en práctica hacia 1620.

\section{$1635-1756$}

En la provincia de Chiapas, hacia 1635 comenzaron a contarse los casados como "tributarios enteros" y los viudos y solteros de ambos sexos como "medios tributarios". Es de destacar que las mujeres viudas y solteras ya no se contaban como tercios tributarios, sino como "medios tributarios". 18

Con respecto a las edades en las que debían tributar, hemos averiguado en documentos de la primera mitad del siglo XVIII que los hombres tributaban de los 16 hasta los 54 años y las mujeres de los 16 hasta los 49 años. ${ }^{19}$ Es el mismo criterio de edad que el dispuesto en los autos de tasación realizados entre 1616 y 1618. Es probable que no haya habido cambios en el criterio de edad desde 1616 hasta 1756. 


\section{$1757-1817$}

En 1757, la Audiencia de Guatemala eximió del tributo a todas las mujeres ya fueran casadas, viudas o solteras y, para compensar esta disminución del tributo, mandó que tributasen el mismo monto todos los hombres desde los 18 años hasta los 49, ya fueran casados, viudos o solteros. ${ }^{20}$ Así desapareció la distinción entre "tributarios enteros" y "medios tributarios", y comenzaron a contarse todos los hombres entre dichas edades como tributarios. ${ }^{21}$ El número de tributarios se convirtió en la suma de los hombres entre 18 y 49 años. Respecto a los tributarios de Chiapas, esta reforma no tardó en ponerse en práctica y se calculó el número de tributarios y el monto del tributo de cada pueblo conforme a las nuevas normas. ${ }^{22}$ Cuando se realizó la última renovación de los padrones de tributarios en la provincia de Chiapas en 1816 y 1817, se calculó el número de tributarios según estas nuevas normas. ${ }^{23}$

De todo lo anterior se desprende que la definición de tributario conoció varios cambios dependiendo de la posesión de casa y milpa, la edad, el sexo y el estado civil: soltero, casado o viudo. Cuando el número de tributarios se convirtió en criterio de tasación en la provincia de Chiapas hacia 1560, el número de tributarios era la suma de los hombres casados, habitualmente con casa y milpa que les permitiera mantener a su familia y pagar el tributo. Como se mencionó, el periodo que va de 1635 a 1756 los hombres tributaban desde los 16 hasta los 54 años y las mujeres desde los 16 hasta los 49 años; y se contaba a los hombres casados por "tributarios enteros" y a los viudos y solteros de ambos sexos por "medios tributarios". A partir de 1757 , todas las mujeres fueron eximidas del tributo y todos los hombres entre 18 y 49 años comenzaron a tributar el mismo monto. Esto quiere decir que el número de tributarios se convirtió en la suma de los hombres con las edades mencionadas.

\section{¿Cómo se fijaba el número de tributarios? El procedimiento de tasación del tributo}

En la primera parte hemos visto el contexto en el que se introdujo el sistema de tasación del tributo y cómo el número de tributarios se convirtió en su criterio principal de tasación. Así, para renovar la tasación siempre se investigaba el número de tributarios y, para su registro, siempre se producía una documentación. Pero, ien qué ocasiones y con qué frecuencia se renovaba la tasación del tributo? ¿Qué documentos se producían al realizar nuevas tasaciones? En las líneas siguientes primero revisamos la frecuencia con que se realizaba la tasación del tributo en la provincia de Chiapas y luego describimos el procedimiento de tasación, prestando atención a los documentos que se producían.

\section{La frecuencia de la tasación}

La tasación del tributo se realizaba individualmente en cada pueblo o, en su caso, en cada parcialidad. En el periodo comprendido entre finales del siglo XVI y principios del siglo XIX, el número de pueblos de la provincia de Chiapas fluctuaba entre 90 y $110,{ }^{24}$ y en cada uno de estos pueblos la Audiencia de Guatemala tenía que estar informada sobre su número de tributarios.

La tasación se realizaba cuando los pueblos de indios presentaban la petición ante la Audiencia, informando sobre la disminución de la población, ${ }^{25} \mathrm{o}$ bien cuando la Audiencia ordenaba la renovación de la tasación para todos o algunos pueblos de su distrito en razón de que había transcurrido un largo tiempo desde la última tasación. ${ }^{26}$ También se llevaba a cabo con ocasión de la visita de un oidor, ${ }^{27}$ así como cuando las encomiendas quedaban vacantes y sus tributos tenían que evaluarse de nuevo. ${ }^{28}$

No eran muy frecuentes las tasaciones que se realizar en casi todos los pueblos de Chiapas en una misma ocasión. Fueron nueve veces - que sepamos-: 1) en $1560-1562,{ }^{29}$ 2) en 1572-1573 (Feria, 1980-456), 3) 
en $\left.1616-1618,{ }^{30} 4\right)$ en $\left.1689-1693,{ }^{31} 5\right)$ en $\left.1701-1704,{ }^{32} 6\right)$ en $\left.1768-1769,{ }^{33} 7\right)$ en $\left.1775-1777,{ }^{34} 8\right)$ en $1792-1796,{ }^{35}$ y 9) en 1816-1817. ${ }^{36}$ Puesto que, aparte de estas tasaciones se realizaban muchas otras para uno o varios pueblos y parcialidades en diversas ocasiones, ${ }^{37}$ el intervalo entre una tasación y la siguiente difería en cada pueblo y cada parcialidad. En efecto, un documento elaborado en 1755 revela que la provincia de Chiapas contaba con ocho pueblos y parcialidades cuyas tasaciones se habían renovado cada cinco años, así como con 27 pueblos y parcialidades cuyas tasaciones no se habían renovado en más de 30 años. ${ }^{38}$ Finalmente, es de destacar que a partir de 1768 ya no se realizaron tasaciones de uno o varios pueblos en distintas ocasiones, sino que sólo se hicieron las tasaciones arriba mencionadas de 6) a 9), y se llevaron a cabo siempre en una misma ocasión en toda la provincia de Chiapas o en su mayor parte.

\section{El procedimiento de tasación y los documentos producidos}

Desde la introducción del nuevo sistema de tasación hacia 1560 hasta la implantación del sistema de intendencia en 1790, la tasación se realizaba grosso modo de la manera siguiente:

Primero, un juez español con comisión de la Audiencia de Guatemala visitaba el pueblo de indios y elaboraba el padrón de tributarios, en el que se inscribían el nombre y la edad de cada tributario y de su familia pertenecientes a la comunidad del pueblo. ${ }^{39}$

Luego, cuando el juez era oidor podía mandar al escribano a hacer la cuenta del número de tributarios y del monto correspondiente del tributo con base en el nuevo padrón de tributarios para expedir el nuevo auto de tasación, ya en el mismo pueblo, ya en otros pueblos de la provincia. ${ }^{40}$

Si el juez era juez de comisión, alcalde mayor o su teniente, el nuevo padrón de tributarios tenía que ser enviado a la Audiencia de Guatemala. ${ }^{41}$ Allí un oficial revisaba el padrón, calculaba el número de tributarios y entregaba un informe al fiscal. Cuando el fiscal aprobaba el padrón con base en el informe, se mandaba a un escribano elaborar el auto de tasación. ${ }^{42}$ Finalmente, el presidente y los oidores de la Audiencia lo firmaban, lo cual significaba la expedición formal del nuevo auto de tasación

En cuanto al padrón de tributarios, se elaboraba una copia. Se guardaba el original en la Audiencia y la copia en el pueblo de indios. La elaboración de la copia se realizaba en el pueblo inmediatamente después de la elaboración del padrón, o bien en la Audiencia después de la aprobación del padrón. ${ }^{43}$ Como mencionaremos más adelante, el juez que realiza el padrón la vez siguiente tendría que revisar esta copia del padrón.

El auto de tasación no siempre seguía el mismo formato, pero a partir de la década de 1570 los autos de tasación contienen los siguientes elementos: ${ }^{44} 1$ ) el hecho de que el padrón de tributarios haya sido revisado; 2) el nuevo número de tributarios -en su caso, desglosado por distintas clases de tributarios-; 3 ) la cuota de un tributario o de cada clase de tributarios; 4) el monto total del tributo con el que el pueblo debía contribuir. Con respecto al auto de tasación, se elaboraban dos copias: una se guardaba en el cabildo del pueblo y la otra en la contaduría de la Audiencia. ${ }^{45}$ Pensamos que el original se guardaba en el archivo de la sala de acuerdos de la Audiencia junto con originales de diversos autos.

Tras la implantación del sistema de intendencia en 1790, el procedimiento de tasación fue el siguiente: primero, subdelegados y jueces de comisión visitaban pueblos de indios y realizaban padrones de tributarios. ${ }^{46}$ Los padrones tenían que ser enviados a la Audiencia, donde el contador los revisaba y calculaba el número de tributarios. Luego, el fiscal los aprobaba. ${ }^{47}$ Hasta aquí el procedimiento era casi el mismo, pero había un cambio importante: el auto de tasación ya no se realizaba. El rateo, que comenzó a hacerse desde fines del siglo XVII, lo sustituyó definitivamente. ${ }^{48}$ 
El rateo resumía de alguna manera el contenido del auto de tasación, pero también señalaba el monto de otras contribuciones - el servicio del tostón y el almud de maíz para la fortificación de Granada en Nicaragua - que se cobraban junto con el tributo. Mientras que el auto de tasación señalaba el monto anual del tributo, el rateo señalaba el monto que debía entregarse separadamente en dos tercios (San Juan y Navidad). En el rateo también se señalaba el destino del tributo, cómo el tributo cobrado se distribuía en diversos fondos y destinatarios, qué porción se destinaba a la real hacienda, al encomendero o a los situados de Barlovento y de Castillo, y qué otra porción se destinaba al diezmo de la iglesia, a los curas párrocos, como concepto de la doctrina de indios y a la caja de la comunidad del pueblo. ${ }^{49}$

\section{Cómo se realizaba el padrón de tributarios}

Hemos visto con qué frecuencia se realizaba la tasación del tributo en la provincia de Chiapas y qué documentos se producían en su procedimiento. Cada vez que se llevaba a cabo la tasación del tributo se elaboraban el padrón de tributarios, el auto de tasación y/o el rateo. En el procedimiento de tasación, es evidente que la elaboración del padrón de tributarios jugaba el papel más importante. Entonces, icómo se elaboraba el padrón de tributarios? A continuación, con base en las reales provisiones de 1581 y 1700 y en una instrucción elaborada en $1767,,^{50}$ mostramos la manera en que se realizaba el padrón de tributarios.

\section{La citación y la colaboración del cura y de los oficiales de la República}

El juez que realizaba el padrón de tributarios tenía la obligación, ante todo, de inscribir a todos los tributarios sin dejar escapar ninguno de ellos. En efecto, en la real provisión de 1581 se mandaba que "contaréis los vecinos y naturales [...] desde el mayor hasta el menor [...] sin dejar persona alguna, [...] informándoos [...] si se han escondido y hurtado por no quedar en el número y padrón". .51 También en la real provisión de 1700 y en la instrucción de 1767 podemos encontrar mandamientos del mismo tipo. ${ }^{52}$

Por ello, llegado al pueblo el juez siempre pedía ayuda al cura doctrinero -el español que mejor conocía el pueblo- - y citaba a los oficiales de la república para que estuviesen presentes en todo el procedimiento de la elaboración del padrón y para que finalmente jurasen que todos los tributarios habían sido empadronados. ${ }^{53}$ Además, el juez elegía y nombraba a algunos indios del pueblo "juramentados", quienes tenían que estar presentes en todo el procedimiento y, al final, prestaban el juramento del mismo contenido. ${ }^{54}$

\section{La consulta del padrón anterior}

Es de destacar también el hecho de que al realizar un nuevo padrón se revisaba el padrón anterior. Cuando el juez llegaba al pueblo, mandaba a los oficiales de la República que le exhibiesen el padrón de tributarios realizado la vez anterior. ${ }^{55}$ En la real provisión de 1581, para no dejar escapar a ningún tributario se mandaba que el juez anduviese casa por casa, averiguase los habitantes "por vista de ojos", "llamándolos por los padrones y cuentas pasadas". ${ }^{56}$ No hemos encontrado ninguna prueba documental de que esta orden se haya respetado en las últimas décadas del siglo XVI, pero un padrón de una parcialidad de Palenque realizado en 1663 aporta una pista: ${ }^{57}$ este padrón hace referencia al padrón anterior para dar fundamento al registro sobre la edad de una mujer tributaria; asimismo, en una partida de un padrón del pueblo de Chiapa elaborado en 1759 se señala en qué partida del padrón anterior estaban inscritos un tributario y su mujer. ${ }^{58}$ Son evidencias de que el juez consultaba el padrón anterior, cuando menos a mediados del siglo XVII así como a mediados del XVIII. 


\section{La consulta de los libros parroquiales}

Los curas doctrineros, tenían la obligación de anotar en libros las actas de bautizos, matrimonios y entierros cada vez que los celebraban en la administración diaria de su parroquia (Morin,1972). Las actas de bautizos $y$ matrimonios en particular jugaban un papel tan importante en la sociedad colonial que se utilizaban en procedimientos judiciales. No sería exagerado decir que los libros parroquiales eran una herramienta para administrar y gobernar la población india.

A partir de mediados del siglo XVII, al juez que realizaba el padrón de tributarios se le impuso una nueva obligación: consultar no sólo el padrón anterior, sino también los libros parroquiales. Se revisaban sobre todo actas de bautismo, para precisar la edad de los tributarios. En el mencionado padrón de una parcialidad de Palenque elaborado en 1663, aparece citado el libro de bautizos como fundamento de la anotación sobre la edad; en el padrón de 1759 del pueblo de Chiapa, se anotaron incluso los meses, de los niños que tenían menos de un año lo cual habría sido imposible si no se hubiera consultado el libro de bautizos. ${ }^{59}$

El hecho de que el libro de bautizos se convirtiera en una referencia obligatoria tenía que ver, pensamos, con el cambio de definición de tributario. A partir de la década de 1620, la edad se convirtió en uno de los criterios más importantes de tasación, y esto seguramente obligó al juez a investigar y registrar la edad de los tributarios con más precisión.

Además, hemos encontradoevidencias documentales de que el juez hacía una minuciosa confrontación entre el padrón anterior y los libros parroquiales. En la mencionada provisión de 1700 , con respecto a los que hubieran muerto después de la realización del padrón anterior, se mandaba anotar al margen de su partida la fecha de su entierro; asimismo, en relación con los menores en el padrón anterior y que ahora se encontraran casados, se mandaba anotar al margen de la partida del padrón anterior el número de partida del nuevo padrón. Concluido el empadronamiento, el juez tenía que enviar no sólo el nuevo padrón, sino también el padrón anterior a la Audiencia de Guatemala, donde se revisaban los dos padrones. Así, la Audiencia mantenía un sistema de vigilancia para que se respetasen estos mandamientos y, si no se encontraban las debidas anotaciones en el margen de cada partida del padrón anterior, se castigaba al juez con la pena de 100 pesos. ${ }^{60}$ De hecho, al margen de cada partida del padrón de tributarios del pueblo de Ixtacomitán, elaborado en 1706, podemos encontrar anotaciones realizadas posteriormente que señalan la fecha del entierro o el número de la partida del nuevo padrón. ${ }^{61}$ Es una prueba de que el juez que realizó el siguiente padrón de este pueblo en 1747 había hecho una minuciosa revisión tanto de este padrón de 1706, como del libro de entierros de esa parroquia. ${ }^{62}$

Finalmente, podemos señalar el caso dela elaboración del padrón de Acala en 1816. En este pueblo, el padrón anterior fue realizado en $1793 \mathrm{y}$, al margen de las partidas del libro de bautizos de la parroquia de Acala, precisamente de las partidas de fechas posteriores a 1793, se encuentran anotaciones realizadas posteriormente que señalan qué personas eran tributarias. ${ }^{63}$ De esto se desprende que el juez que realizó el padrón de este pueblo en $1816^{64}$ había hecho una revisión exhaustiva del libro de bautizos para inscribir en ese padrón a todos los indios tributarios, incluyendo a los que habían nacido a partir de 1793, fecha de realización del padrón anterior.

\section{El padrón de tributarios}

Hemos visto el procedimiento de la tasación y, en particular, el de la elaboración del padrón de tributarios: el juez realizaba el padrón con la presencia y la colaboración del cura doctrinero y de los oficiales de la República consultando minuciosamente el padrón anterior y los libros parroquiales. Como resultado de este procedimiento, entonces, ¿qué elementos se registraban en el padrón de tributarios? 
el nombre, el apellido y la edad de él o ella. Cuando tenía hijos también se registraban su nombre y edad. Para dar ejemplos concretos, ponemos abajo dos partidas de la primera categoría (casados tributarios enteros):

[Partida 4] Manuel Pesa de 44 años, casado en primeras nupcias con Victoria Sánchez, de quién tiene al soltero y soltera; y en segundas con María Nuri Viernes de 40 años, tienen a Marcelino de 6 meses; y ella tiene de otro matrimonio con Vicente Methaa los huérfanos.

$[\ldots]$

[Partida 30] Sebastián de León de 29 años y Manuela Nigenda, su mujer de la misma edad. Tienen a Juana de 3 años y Pedro Martín de 7 meses.

tributarios; entre las páginas 89 y 90, que son las últimas, el alcalde mayor declara el fin del empadronamiento. Al final del libro se encuentra anexada una certificación del cura doctrinero que hacía constar su presencia en el procedimiento y declaraba que no había fraude.

En la parte inicial, en la que el alcalde mayor declara el comienzo del empadronamiento, menciona la presencia del cura doctrinero en el procedimiento, la entrega de los libros parroquiales por parte del cura y la presencia de los nueve oficiales de la República, ocho "juramentados", dos intérpretes y dos testigos de asistencia del alcalde mayor.

Luego siguen 1,115 partidas que se encuentran clasificadas y ordenadas por diez categorías, principalmente según el sexo y el estado civil: casado, viudo o soltero: I. Casados tributarios enteros (partidas de 1 a 384); II. Casados con extrañas (de 385 a 440); III. Clase de viudos (de 441 a 460); IV. Clase de solteros (de 461 a 555); V. Mujeres casadas con extraños (de 556 a 603); VI. Clase de viudas (de 604 a 743); VII. Clase de solteras (de 744 a 893); VIII. Hombres y mujeres reservados (de 894 a 1020); IX. Clase de huérfanos ${ }^{66}$ (de 1021 a 1108); X. Clase de huidos (de 1109 a 1115 ).

Veamos el contenido de cada partida. Primero están inscritos el nombre, el apellido y la edad de la persona que encabeza esa partida y luego, cuando tenía cónyuge,
Como hemos señalado anteriormente, respecto a los niños menores de un año se registraba incluso cuántos meses tenían. También se puede destacar que en la partida 4 se señala con claridad la relación de parentesco, anotando para los hijos del matrimonio anterior el nombre del padre o la madre fallecido. Sobre estos hijos, la misma partida sólo dice "soltero y soltera" y "huérfanos", ${ }^{67}$ así que podría parecer que no siempre se registraban el nombre y la edad de los niños. Sin embargo, si revisamos todo el padrón podemos encontrar a estos hijos inscritos independientemente en sus propias categorías. Primero citamos dos partidas correspondientes una a la categoría de solteros y otra a la de solteras:

[Partida 461] Domingo Julián Pesa de 22 años.

[...]

[Partida 748] Petrona Pesa de 19 años.

De los 95 solteros y las 150 solteras inscritos en estas categorías, sólo estos dos tienen el apellido Pesa y seguramente eran los hijos solteros mencionados en la partida 4. Abajo citamos una partida de la categoría de huérfanos: 
[Partida 1027] Manuela de 12 años y María de 8, hijas de Vicente Metaa y de María Nuri Viernes. Queda[n] con su madre.

Dado que en esta partida se señalan el nombre y el apellido de sus padres, podemos afirmar con toda certeza que estas dos niñas eran las huérfanas mencionadas en la partida 4.

Por otra parte, es interesante hacer un análisis prestando particular atención a la edad de los que encabezan cada partida. Los hombres casados de las categorías I y II (440 partidas) tenían edades entre 18 y 49 años; los viudos (20 partidas) entre 19 y 49 años; y los solteros (95 partidas) entre 18 y 32 años. Como hemos visto en la primera parte, en la Audiencia de Guatemala a partir de 1757 todas las mujeres fueron eximidas del pago del tributo, y a los hombres con edades entre 18 y 49 años, ya fueran casados o solteros, se les cargó el mismo tributo. En este padrón, elaborado en 1759, se registraron los casados, los viudos y los solteros según el nuevo criterio de edad. Con respecto a las mujeres, todas exentas de tributación, las casadas con extraños (48 partidas) tenían edades entre 14 y 48 años, las viudas (140 partidas) entre 20 y 49; años y las solteras (150 partidas) entre 18 y 44 años. En cuanto a los "reservados" de la categoría VIII, se encontraban 17 eximidos por incapacidad corporal y enfermedad que tenían edades entre 18 y 59 años, y 110 eximidos por ser mayores que tenían edades entre 50 y 71 años.

En este padrón hay 466 partidas en las que se registraron hijos como en los casos de las partidas 4 y 30, cuya distribución es de la siguiente manera: los casados tributarios enteros (260 partidas), los casados con extrañas (0 partidas), los viudos (1l partidas), los solteros (0 partidas), las casadas con extraños (31 partidas), las viudas (82 partidas), las solteras (35 partidas) y los reservados (47 partidas). Como es de esperar, los hijos registrados en estas partidas tenían edades entre 0 y 17 años y, en cuanto a los huérfanos de la categoría IX, se puede observar la misma variedad de edades. En esta distribución es de destacar que no se registró ningún hijo —ni se señaló si tenían hijosen las partidas de los hombres casados con mujeres extrañas. Contrasta con el hecho de que se registraran hijos en 31 partidas de mujeres casadas con hombres extraños y se señalara con toda claridad que no tenían hijos en las demás partidas de esta categoría. Esto ha de indicar que la calidad de la madre se transmitía a los hijos sin que la del padre tuviera importancia. ${ }^{68}$

En la última parte, tras las 1,115 partidas, el alcalde mayor declara el fin de la elaboración del padrón señalando que los oficiales de la República y los "juramentados" prestaron el juramento de que todos los indios fueron inscritos sin ninguna excepción. Al final se encuentran las firmas del acalde mayor, el cura doctrinero, el escribano del cabildo de Chiapa y los dos testigos de asistencia del alcalde mayor.

De todo lo anterior se desprende que en este padrón se registraron todos los indios pertenecientes a la comunidad del pueblo de Chiapa edades comprendidas entre los 0 y los 70 años. Dado que la definición de tributario en 1759 correspondía con los hombres de edades entre 18 y 49 años, se puede sacar el número de tributarios de este padrón sumando el número de los casados, los viudos y los solteros inscritos en las categorías de I a IV: 555 tributarios. Por otra parte, para sacar la población india del pueblo de Chiapa de ese momento hay que contar todas las personas, incluyendo los cónyuges y los hijos, en todas las 1,115 partidas. Según nuestro cálculo, era de unas 2,360 personas. ${ }^{69}$

\section{Cambios de los elementos en las partidas}

Casi todos los padrones de tributarios que hemos encontrado de la provincia de Chiapas fueron realizados durante el siglo XVIII y principios del XIX. ${ }^{70}$ De los padrones del siglo XVII sólo hemos localizado uno, el de una parcialidad del pueblo de Palenque elaborado en 1663. ${ }^{71}$ De los padrones del XVI, desgraciadamente no hemos encontrado ninguno, aunque podemos usar como 
una referencia un padrón del pueblo de Guilocingo, de la vecina provincia de Soconusco, elaborado en 1582 (Gasco, 1990). A pesar de esta limitación en las fuentes disponibles, a continuación tratamos de esbozar los cambios que se produjeron en los elementos que componían las partidas del padrón de tributarios.

En primer lugar, pensamos que durante el periodo comprendido entre finales del siglo XVI y mediados del siglo XVIII hubo cambios importantes. Veamos una partida del padrón de Guilocingo elaborado en 1582, y otra del padrón de una parcialidad de Palenque realizado en 1663, en las cuales podemos observar esos cambios. Las dos partidas son de casados, tributarios enteros:

[Partida 3 del padrón de Guilocingo de 1582] Domingo Hernández, alcalde, de edad de 45 años y Cecilia, su mujer, de 20 años. Tienen tres hijos entenados de ella, el mayor de 8 años, y casa y solar, en que viven, y una huérfana pobre, que se llama María, de 14 años. Tiene una milpa de cacao de 3,200 árboles, y hace milpa de maíz de invierno y de verano. Cría gallinas de Castilla y de la Tierra. Paga de tributo 30 zontes de cacao. Puede pagar una carga de cacao. ${ }^{72}$

[Partida 2 del padrón de una parcialidad de Palenque de 1663] Diego Méndez de edad, según el libro de bautismos, de 52 años y Margarita Méndez, su mujer, de 46 según el padrón antecedente. No tienen hijos. Tributando tres años, el susodicho debe quedar reservado. Casa y milpa. ${ }^{73}$

Estas dos partidas tienen un punto en común con las partidas del padrón de Chiapa de 1759: se registraron el nombre, el apellido y la edad del hombre casado y de su mujer. Sin embargo, en el caso del padrón de Guilocingo de 1582 se registraron también los principales bienes (casa, milpa y animales domésticos, etcétera) que poseía cada tributario, evaluándose el monto del tributo que podía pagar. En el caso del padrón de Palenque de 1663, aunque ya en forma bastante sencilla, también se registraron "casa y milpa". Y en los padrones del siglo XVIII y principios del XIX que hemos localizado, nunca se encuentra este tipo de registro sobre los bienes que poseían los tributarios. ${ }^{74}$ Como hemos visto en la primera parte de este trabajo, la definición de tributario conoció un cambio importante hacia 1620 dado que la posesión de aquellos bienes dejó de tomarse en cuenta, mientras que la edad se convirtió en el criterio decisivo. Esto explica bien la desaparición del registro de aquellos bienes en el padrón de tributarios.

Por lo que respecta al registro de los hijos de tributarios, los padrones de este periodo también tuvieron un cambio significativo. En el padrón de Guilocingo, de 1582, se presta menos atención a los hijos, omitiendo el nombre y la edad en muchos casos. Sobre este punto, no sabemos cómo se hacía en los padrones del siglo XVII: no podemos recurrir al padrón de Palenque de 1663 ya que sólo se compone de tres partidas, además de que ningún tributario tenía hijos. Pero como hemos visto en el caso del padrón de Chiapa de 1759, se registraron el nombre y la edad de todos los hijos en los padrones realizados desde principios del siglo XVIII hasta mediados del mismo siglo. ${ }^{75}$ Según la Recopilación de Indias, se expidió en 1618 una disposición donde constaba que "en los padrones de las tasas se pongan los hijos y sus edades". ${ }^{76}$ Es muy probable que, conforme a esta disposición, se haya comenzado a registrar el nombre y la edad de todos los hijos. También es de notar que, casi al mismo tiempo que se expidió esa disposición, la edad se convirtió en el criterio determinante para la definición de tributario, lo que hemos visto en la primera parte de este trabajo. Seguramente por ello comenzaron a registrar la edad de todos los indios, ya fueran niños, adultos o ancianos.

Finalmente, señalamos que los padrones conocieron otros cambios importantes en el periodo posterior a 1767. En ese año, la Audiencia de Guatemala elaboró una nueva instrucción para los jueces que realizaran el padrón de tributarios ${ }^{77}$ en la que no sólo se mandaba cambiar el formato y la composición del padrón, ${ }^{78}$ sino 
también se ordenaba que dejasen de registrar la edad de todas las mujeres. Como hemos observado en la primera parte de este trabajo, a partir de 1757 en la Audiencia de Guatemala, todas las mujeres fueron eximidas del pago del tributo, y los hombres con edades entre 18 y 49 años comenzaron a tributar el mismo monto. Así desapareció la razón de registrar la edad de las mujeres y se ajustó la eficiencia del trabajo al realizar el padrón. Por otra parte, en esta instrucción de 1767 se creó una nueva categoría de "próximos a tributar", en la que habían de caer los hombres con edades entre 13 y 17 años. Dado que sólo los hombres con edades determinadas eran tributarios, se intentó empadronar con más precisión a los tributarios de la próxima generación. En los padrones realizados en la provincia de Chiapas en 1795-1796 y en 1816-1817, hemos averiguado que estos cambios habían sido realizados. ${ }^{79}$

\section{Reflexiones finales}

En este trabajo hemos indagado sobre ladefinición de tributario, cómo se fijaba su número de tributarios y bajo qué sistema administrativo se producía su documentación. Hemos mostrado que en la provincia de Chiapas, hacia 1560 el número de tributarios se convirtió en el principal criterio de tasación del tributo y que la definición de tributario conoció varios cambios dependiendo de la posesión de bienes como casa y milpa, la edad, el sexo y el estado civil: soltero, casado o viudo. Además, hemos aclarado que para fijar el número de tributarios de cada pueblo se elaboraba el padrón de tributarios y para ello se realizaba una minuciosa revisión del padrón anterior y de los libros parroquiales. También hemos observado en los distintos elementos que contenía cada partida del padrón, los cuales seguramente pueden explicarse por la definición cambiante de tributario. Al final hemos señalado que a partir de 1767 se registró la edad sólo para los hombres. Hemos realizado este trabajo con el fin de mostrar la importancia del estudio crítico sobre el número de tributarios en la historia de la población.
Para concluir, señalamos algunos planteamientos para el estudio histórico de la población.

En primer lugar, tenemos que prestar atención a la definición cambiante de tributario, sobre todo si ordenamos cronológicamente los datos sobre el número de tributarios de todo el periodo colonial y si comparamos los datos de distintas calidades en un sentido riguroso, a pesar de que todos esos datos aparecen como "tributarios" en sus fuentes.

En segundo lugar, la tasación del tributo y la renovación del número de tributarios se realizaba no sólo para todos los pueblos de una provincia en una misma ocasión, sino también para uno o varios pueblos en distintas ocasiones. Esto quiere decir que en cada pueblo se realizaba el padrón de tributarios en distintas fechas, las cuales podían diferir incluso en dos o tres décadas. Así, es posible que el número total de tributarios de una alcaldía mayor - un corregimiento o una gobernación - sea la suma de datos con fechas muy variadas. Esta posibilidad aumentará a medida que la región estudiada se extienda entre varios distritos administrativos.

Por ello, tendremos que asumir en cierto grado una disminución de la precisión al analizar tendencias demográficas de una amplia región durante un largo periodo.

Por otra parte, si usamos el pueblo como unidad de análisis para estudiar la evolución demográfica de una región relativamente pequeña compuesta de pueblos, podemos prescindir del problema sobre las fechas de los datos. Así sólo necesitaremos prestar atención a la definición cambiante de tributario para observar con más precisión las influencias que ejercieron en la población india los fenómenos naturales y sociales.

Además de lo anterior, podemos señalar la importancia del padrón de tributarios como fuente histórica: en el padrón se inscribían todos los indios pertenecientes al pueblo o la parcialidad. Si además de al padrón de tributarios se puede recurrir al padrón de habitantes ya los libros parroquiales elaborados 
por el cura párroco, podremos aproximarnos a la población india con métodos más diversos. Por ejemplo, combinando padrones de tributarios y padrones de habitantes hemos analizado la proporción cambiante entre los indios y los no indios de una región (ObaraSaeki, 2010). También contamos con un estudio que llevó a cabo Herbert Klein bajo el método de la "reconstitución de familias" utilizando tanto los libros parroquiales como el padrón de tributarios (Klein, 1986).

Conociendo en profundidad la historia de la tasación y las características del número de tributarios podemos plantear estudios históricos de la población más rigurosos y más fértiles.

\section{Notas}

${ }^{1}$ Sobre el factor de conversión, véase Borah y Cook, 1960: 75-103; Cook y Borah, 1998, vol. 1, pp. 271-283; vol. 2, pp. 58-60; Arias de Blois, 1994, pp. 316-318 y 320-322.

${ }^{2}$ Por ejemplo, Cook y Borah (1998, vol. 1, pp. 265-270) ha realizado un estudio sobre la definición cambiante de tributario en la Nueva España durante toda la época colonial. Sobre el sistema tributario del siglo XVI, ellos se basaron principalmente en una obra clásica de José Miranda (1952).

${ }^{3}$ En el distrito de la Audiencia de Guatemala existían dos tipos de jurisdicción: la comarca inmediata de Santiago de Guatemala, gobernada por alcaldes mayores y corregidores nombrados directamente por la Audiencia, y las provincias, en las cuales los gobernadores y alcaldes mayores con títulos reales ejercían un control relativamente autónomo de la Audiencia. A partir de 1578, la provincia de Chiapas se convirtió en jurisdicción del segundo tipo y fue gobernada por un alcalde mayor nombrado directamente por el rey. En 1769, la alcaldía mayor de Chiapas se dividió en dos alcaldías, una con sede en Tuxtla y otra en Ciudad Real. En 1790, como consecuencia de las reformas borbónicas, se creó la intendencia de Chiapas, en la que fueron incluidas no sólo las dos alcaldías mayores mencionadas, sino también la gobernación del Soconusco (Pastor, 1998: 84-88 y 136-137; Gerhard, 1991: 120).

${ }^{4}$ Hemos tratado un caso concreto de los indios del pueblo de Chiapa en un trabajo anterior: Obara-Saeki, Ladinización sin mestizaje, pp. 79-81.

5 AGI, Guatemala, 393, libro 1, ff. 155r-158v. [Real provisión]. Madrid, 23 de febrero de 1536.

${ }^{6}$ Hemos tratado las tasaciones de 1546 y 1549 en un trabajo anterior (Obara-Saeki, 2010: 84-91).

${ }^{7}$ Sobre esta reforma en la Nueva España, véase Miranda (1952). Respecto a la reforma en el distrito de la Audiencia de Los Confines, nos dan una pista los documentos siguientes: AGI, Guatemala, 9A, r. 23, n. 93, ff. lr y 3v-4r. [Carta de Antonio Mejía, oidor de la audiencia de Guatemala]. Guatemala, 30 de julio de 1557; AGI, Guatemala, 386, libro 1, ff. 297r-298r. [Carta del rey al presidente y los oidores de la audiencia de Los Confines]. Valladolid, 17 de junio de 1559.

${ }^{8}$ AHN, Diversos-Colecciones, 24, n. 59. [Carta de los frailes dominicos a Felipe II]. Ciudad Real, 1 de abril de 1562.

9 AGI, Guatemala, 168, [Carta de doce dominicos al rey. Guatemala, 1 de diciembre de 1570], ff. lr-lv; AGI, Guatemala, 169, [Carta de fray Juan de Castro, prior, al rey. Guatemala, 6 de octubre de 1574], f. lr.

${ }^{10}$ En la década de 1560, la posesión de milpa era un criterio importante en la definición del tributario: AGI, Guatemala, 168, [Carta de doce dominicos al rey. Guatemala, 1 de diciembre de 1570], ff. lr-lv. En el caso del pueblo de Guilocingo en la gobernación del Soconusco, el juez que realizó el padrón en 1582 investigó y registró para cada tributario la posesión de los bienes como casa, milpa o animales domésticos (Gasco, 1990).

"1 AGI, Guatemala, 168, [Carta de doce dominicos al rey. Guatemala, 1 de diciembre de 1570], ff. Ir-lv; AGI, Guatemala, 169, [Carta de fray Juan de Castro, prior, al rey. Guatemala, 6 de octubre de 1574], f. lr; AGI, Patronato, 183, n. 1, r. 11, f. 6r. [Relación de fray Pedro de Feria, obispo de Chiapas]. Sin fecha [ca. 1585]; AGI, 
México, 3102, "Número 1l. Primera pieza con 154 fojas", ff. 40r-47r. [Informe de don Fructus Gómez, deán de la catedral de Chiapas]. Ciudad Real, 1 de octubre de 1611; AGI, Guatemala, 57, "Comisión a don Juan de Vitoria para que cuente el pueblo de Tecpatán [...]”, f. lv. [Instrucciones para la cuenta y padrón]. Guatemala, 3 de mayo de 1581. Agradezco a Juan Pedro Viqueira, quien me proporcionó generosamente la transcripción del documento de AGI, México, 3102, "Número 1l. [...]", ff. $40 \mathrm{r}-47 \mathrm{r}$.

${ }^{12}$ Es una suposición basada en el caso de la Nueva España del periodo entre la década de 1550 la de 1580 (Miranda, 1952: 309 y 325-326; Cook y Borah, 1998, vol. 1, pp. 36 y 41).

${ }^{13}$ A GI, Guatemala, 57, “Comisión [...]”,f. lv. [Instrucciones para la cuenta y padrón]. Guatemala, 3 de mayo de 1581; AGI, México, 3.102, "Número 11 [...]”, ff. 40r-47r. [Informe de don Fructus Gómez]. Ciudad Real, 1 de octubre de 161l. En estos documentos se consideran tributarios solamente los casados, los viudos, los solteros y las viudas, y nunca menciona a las mujeres solteras.

${ }^{14}$ Véanse los siguientes autos de tasación de los pueblos de la provincia de Chiapas: AGI, Escribanía, 334B, "Pedro Arnáez de Solórzano, como padre legítimo [...]", ff. 126v-135v (Zinacantán, 1616); ff. 135v-140v (San Felipe, 1616); ff. 118r-126v (Ixtapa, 1617); ff. 140v-148r (Bachajón, 1618); AGI, Escribanía, 334B, "Autos del fiscal de su majestad de esta real audiencia contra don Pedro de la Tovilla [...]", ff. 14r-14v (Copanaguastla, 1635); ff. 15r-15v (Tecoluta, 1635).

${ }^{15}$ AGI, Escribanía, 334B, "Pedro Arnáez [...]", ff. 118r-153v; AGCA, Chiapas, A3, leg. 355, exp. 4517, ff. lr-2r; exp. 4518, ff. 2r-3r y 4r-6r; y exp. 4519.

${ }^{16}$ La única excepción que hemos encontrado es: AGI, Escribanía, 334B, “Autos [...]”, ff. 16v-17r. Tasación del pueblo de Ixtapilla, parcialidad [de] don Pedro de la Tovilla y Pineda. Chamula, 19 de junio de 1635. Para una lista de los autos de tasación posteriores a 1620, véase la nota 44
${ }^{17}$ Recopilación de Indias..., vol. 2, libro 6, título 5, ley 7, ff. 208v-209r.

${ }^{18}$ Suponemos que este cambio haya ocurrido hacia 1635 con base en el análisis de tres documentos: AGCA, Chiapas, A3, leg. 355, exp. 4524, ff. 3v-5v. Auto de tasación del año de 627 [del pueblo de Chiapa]. Santiago de Guatemala, 30 de marzo de 1627; el mismo expediente, ff. 10v-12r. Auto de tasación del año de 1637 [del pueblo de Chiapa]. Santiago de Guatemala, 21 de agosto de 1637; AGCA, Guatemala, A3, leg. 825, exp. 15207, f. 4r. [Informe sin firma sobre los tributarios de los pueblos de Chiapas bajo administración dominica]. [Sin fecha]. Para este periodo hay muchos documentos en los que se puede observar la manera de contar tributarios. Véase, por ejemplo, AGCA, Guatemala, A3, leg. 1601, exp. 2639; y AGCA, Guatemala, A3, leg. 2316, exp. 34167 [2].

${ }^{19}$ Por ejemplo, véase el padrón de tributarios de Palenque de 1703 (AGCA, Chiapas, A3, leg. 357, exp. 457l, ff. 4r-17r), el de Chiapa de 1746 (AGCA, Guatemala, A3, leg. 2803, exp. 40536; AGCA, Chiapas, A3, leg. 353, exps. 4506 y 4507) y el de Acala de 1752 (AGCA, Chiapas, A3, leg. 361, exp. 4.672).

${ }^{20}$ AGI, Guatemala, 239, “Año de 1758. Testimonio de los autos hechos [...]”, ff. lr-lv. Real cédula. Buen Retiro, ll de diciembre de 1756; y ff. 9v-1lr. Auto. Guatemala, 6 de septiembre de 1757.

${ }^{21}$ La nueva manera de contar tributarios se puede observar fácilmente, por ejemplo, en AGCA, Chiapas, A3, leg. 300, exp. 4058. [Sumario de padrones de algunos pueblos de la alcaldía mayor de Ciudad Real]. Guatemala, 30 de diciembre de $1769.5 \mathrm{ff}$

${ }^{22}$ AGI, Guatemala, 549, "Año de 1766. Testimonio de la real cédula [...]”, ff. 3v-7r. Informe [del contador de cuentas reales y resultas de la Audiencia de Guatemala] Guatemala, 24 de diciembre de 1761.

${ }^{23}$ Para la referencia de los padrones de tributarios elaborados en 1816 y 1817, véase la nota 79.

${ }^{24}$ AGI, Guatemala, 161, [Carta del obispo fray Andrés de Ubilla al rey. 28 de marzo de 1595], ff. 3r-3v; y AHDSC, 
fondo diocesano, San Cristóbal, IV. D. 4. [Informe sobre los tributarios del obispado de Chiapas y Soconusco], sin fecha [ca. 1807-1812].

${ }^{25}$ Por ejemplo, AGCA, Chiapas, A3, leg. 296, exp. 3999. Memoria de los naturales empadronados en el pueblo de Chiapa [...]. [ca. 1746]; leg. 358, exp. 4602, ff. 5r-5v. [Petición del pueblo de Chiapa]. 171l; leg. 361, exp. 4672, ff. lr-lv. [Petición del pueblo de Acala. ca. 1752].

${ }^{26}$ Por ejemplo, AGI, Escribanía, 369B, "Testimonio del lo cuaderno de autos hechos en el juicio de la residencia que dan Martín González de Vergara [...]”, ff. 64r-69r. Testimonio de dos reales provisiones. Guatemala, 14 de abril de 1700 .

${ }^{27}$ Los siguientes tres, entre otros, son los oidores que visitaron la provincia de Chiapas e hicieron nuevos autos de tasación: Cristóbal de Ascoeta (1572-1573); Luis de las Infantes y Mendoza (1635-1636); y José de Scals (1689-1690). Véase AGCA, Chiapas, A3, leg. 353, exp. 4512, ff. 6r-7r y 8r-9r; AGI, Escribanía, 334B, “Autos [...]", ff. 14r-14v y 15r-15v; AGCA, Chiapas, A3, leg. 357, exps. 4,550 y 4,555 .

${ }^{28}$ Recopilación de Indias..., vol. 2, libro 6, título 5, ley 35, f. 2l3v; AGI, Guatemala, 102, n. 35, ff. lr-6v. [Título de la encomienda de los pueblos de Escuintenango y Aquespala]. 165l; AGCA, Chiapas, A3, leg. 357, exp. 4,546. [Petición de Juan Macal de Meneses]. Ciudad Real, 7 de julio de 1676.

${ }^{29}$ AHN, Diversos-Colecciones, 24, n. 59.

${ }^{30}$ AGI, Escribanía, 334B, "Pedro Arnáez [...]”, ff. 118r-153v; AGCA, Chiapas, A3, leg. 355, exp. 4523, ff. 4r-5v.

${ }^{31}$ AGCA, Chiapas, A3, leg. 1, exp. 1, ff. 4r-14v; Viqueira, 1997: 170.

32 AGI, Escribanía, 369B, "Testimonio [...]”; Viqueira, 1997: 170.

33 AGI, Guatemala, 566, "Cuaderno 2ㅇ. Testimonio del expediente sobre rebaja de tributarios [...]", ff. 4lv-66r; AGCA, Chiapas, A3, leg. 300, exp. 4,058; leg. 302, exp. 4,064, ff. 90r-114r.

${ }^{34}$ AGCA, Chiapas, A3, leg. 302, exp. 4065.

${ }_{35}$ AGCA, Guatemala, A3, leg. 439, exp. 8984.
${ }^{36}$ Para la referencia de los 71 padrones de tributarios elaborados en 1816 y 1817, véase la nota 79.

${ }^{37}$ AGCA, Guatemala, A3, leg. 1601, exp. 2639, ff. 214r-280r. [Libro de cuenta y razón del tributo de los pueblos del reino de Guatemala. 1678]; AGCA, Chiapas, A3, leg. 299, exp. 4043. Ciudad Real. Guatemala. 1755. [Relación de rateos del escribano de Ciudad Real, Francisco Javier de Ancheta].

${ }^{38}$ AGCA, Chiapas, A3, leg. 299, exp. 4043. Ciudad Real. Guatemala. 1755. [Relación de rateos de Francisco Javier de Ancheta, escribano]. $140 \mathrm{ff}$.

${ }^{39}$ Más adelante trataremos con más detalle cómo se elaboraba el padrón de tributarios.

${ }^{40}$ Recopilación de Indias..., vol. 2, libro 6, título 5, leyes 53 y 54, f. $216 r$.

${ }^{41}$ AGI, Guatemala, 57, “Comisión [...]”, f. 2r. [Instrucciones para la cuenta y padrón]. Guatemala, 3 de mayo de 1581; AGI, Escribanía, 369B, "Testimonio [...]”, f. 67v. Testimonio de dos reales provisiones. Guatemala, 14 de abril de 1700; AGI, Guatemala, 560, "Instrucción a que se han de arreglar los gobernadores, alcaldes mayores, corregidores [...]”, f. 5v, artículo 22. [Instrucciones para la cuenta y padrón]. Guatemala, 13 de julio de 1767.

${ }^{42}$ Con respecto a los informes entregados al fiscal, hemos encontrado solamente tres: AGCA, Chiapas, A3, leg. 361, exp. 4682. [Sumario de padrones de tributarios de los pueblos de Tecpatán, Coapilla, Tapalapa y Pantepec], sin fecha ni firma [ca. 1757]. [3 ff.]; AGCA, Chiapas, A3, leg. 300, exp. 4058. [Sumario de padrones de algunos pueblos de la alcaldía mayor de Ciudad Real] Guatemala, 30 de diciembre de 1769; AGCA, Chiapas, A3, leg. 303, exp. 4092, ff. 1r-10v. [Informe del contador mayor Tomás Wading al fiscal], Guatemala, 30 de septiembre de 1794. El informe de 1769 fue firmado por José Sánchez de León, quien aparece en otro documento como "oficial mayor en los expedientes de padrones" (AGCA, Chiapas, A3, leg. 300, exp. 4057, ff. 25r-25v. [Carta del oficial mayor José Sánchez de León]. Guatemala, 29 de octubre 1772). En cuanto a la aprobación del padrón por parte del fiscal, véase AGI, 
Escribanía, 369B, “Testimonio [...]”, f. 67v. Testimonio de dos reales provisiones. Guatemala, 14 de abril de 1700; AGCA, Chiapas, A3, leg. 303, exp. 4092, ff. 12r-13r. [Carta de Tomás Wading, contador]. Guatemala, 30 de septiembre de 1794. Después de la aprobación del padrón, los escribanos parecen haber elaborado el auto de tasación: AGCA, Chiapas, A3, leg. 356, exp. 4531, f. lr. [Petición de don Diego de Escobar, escribano de cámara, presentada en la Audiencia de Guatemala el 17 de julio de 1654].

${ }^{43}$ AGI, Escribanía, 369B, "Testimonio [...]", f. 67v; AGI, Guatemala, 560, “Instrucción [...]”, f. 2r, artículo 3.

${ }^{44}$ Hemos investigado los siguientes autos de tasación de los pueblos de la provincia de Chiapas, elaborados desde mediados del siglo XVI hasta mediados del XVII: dos autos de 1541 (AGI, Patronato, 75, n. 3, r. 1 (4), ff. 59r-62v); tres de 1561-1562 (AGI, Justicia, 292, "Guatemala. Año de 1572. El fiscal de su majestad con Antonio Díaz [...]”, ff. 24r-26v); cuatro de 1572-1573 (AGCA, Chiapas, A3.16, leg. 353, exp. 4512, ff. 6r-9r; y AGI, Guatemala, 56, "Relación de las derramas", ff. 170r-172r); nueve de 1616-1618 (AGI, Escribanía, 334B, "Pedro Arnáez [...]", ff. 118r-153v; AGCA, Chiapas, A3, leg. 355, exp. 4517, ff. lr-2r; exp. 4,518, ff. 2r-6r; y exp. 4519); tres de 1626-1627 (AGI, Escribanía, 334B, "Pedro Arnáez [...]", ff. 153v-156v; y AGCA, Chiapas, A3, leg. 355, exp. 4.524, ff. 3v-5v); ocho de 1635-1637 (AGI, Escribanía, 334B, “Autos [...]”, ff. 14r-17r; AGCA, Chiapas, A3, leg. 355, exp. 4.523, ff. 2r-5v; y exp. 4524, ff. 10v-12r); y uno de 1663 (AGCA, Chiapas, A3, leg. 357, exp. 4.547, f. 3lr). A demás, hemos consultado 98 autos de tasación de los pueblos de la provincia de Chiapas y la gobernación del Soconusco realizados entre 1681 y 1742: AGCA, Chiapas, A3, leg. 298, exps. 4019 y 4022; leg. 299, exp. 4043; leg. 355, exp. 4520; leg. 357, exps. 4550-4557, 4559-4568, 4570-4591; leg. 358, exps. 4592 4599, 4601, 4603-4609, 4611, 4613, 4615, 4618, 4621, 4625 y 4626; y leg. 359, exps. 4627, 4628, 4631, 4632 y 4638. Agradezco a Gudrun Lenkersdorf, quien me proporcionó generosamente la transcripción de todo el documento de AGI, Guatemala, 56, "Relación de las derramas".

${ }^{45}$ Para la referencia de los autos de tasación realizados entre 1616 y 1663, véase la nota 44.

${ }^{46}$ AGCA, Chiapas, A3, leg. 303, exp. 4092, ff. 18r-19r. [Carta de José Farrera a la Audiencia de Guatemala]. Tonalá, 29 de diciembre de 1794. Para la referencia de los padrones realizados en 1816 y 1817, véase la nota 70 .

47 AGCA, Chiapas, A3, leg. 303, exp. 4092, ff. 12r-13r. [Carta de Tomás Wading, contador]. Guatemala, 30 de septiembre de 1794.

${ }^{48}$ AGCA, Chiapas, A3, leg. 303, exp. 4092; y AGCA, Guatemala, A3, leg. 439, exp. 8984, ff. 25-81.

${ }^{49}$ El rateo se llamaba también "razón del tributo". Muchos ejemplos del rateo se encuentran en AGCA, Chiapas, A3, leg. 299, exp. 4043. Ciudad Real. Guatemala. 1755. [Relación de rateos de Francisco Javier de Ancheta, escribano]. $140 \mathrm{ff}$.

50 La Audiencia de Guatemala instruía sobre cómo realizar el padrón en las reales provisiones donde se mandaba a los jueces realizar nuevos padrones. Las dos provisiones que utilizamos en este trabajo constituyen sus ejemplos: AGI, Guatemala, 57, "Comisión a don Juan de Vitoria para que cuente el pueblo de Tecpatán [...]”. Guatemala, 3 de mayo de 1581. 2 ff.; AGI, Escribanía, 369B, "Testimonio [...]", ff. 64r-69r. Testimonio de dos reales provisiones. Guatemala, 14 de abril de 1700. En 1767, en la Audiencia de Guatemala, se elaboró como documento independiente una nueva instrucción sobre la realización del padrón de tributarios: AGI, Guatemala, 560, "Instrucción a que se han de arreglar los gobernadores, alcaldes mayores, corregidores [...]". Guatemala, 13 de julio de 1767. $6 \mathrm{ff}$.

${ }^{51}$ AGI, Guatemala, 57, “Comisión [...]”, f. lv.

${ }^{52}$ AGI, Escribanía, 369B, "Testimonio [...]”, ff. 66v-67r; AGI, Guatemala, 560, “Instrucción [...]”, f. lv, artículo 1. 53 AGI, Guatemala, 57, "Comisión [...]”, ff. lv-2r; AGI, Guatemala, 560, "Instrucción [...]", ff. 2r-2v, artículos 5 y 7.

${ }^{54}$ Véase, por ejemplo, AGCA, Chiapas, A3, leg. 357, exp. 4.547, f. 33r. [Padrón de tributarios de la parcialidad 
de doña Magdalena de Mazariegos en el pueblo de Palenque], Palenque, 10 de marzo de 1663; AGCA, Chiapas, A3, leg. 361, exp. 4672, f. 2v. Cuenta y numeración de los naturales del pueblo de San Pablo de Acala [...], 1752; AGCA, Chiapas, A3, leg. 300, exp. 4045, f. lr. Numeración de los naturales del pueblo de Santo Domingo de Chiapa [...], Chiapa, 3 de noviembre de 1759.

55 AGI, Escribanía, 369B, "Testimonio [...]”, f. 67v; AGI, Guatemala, 560, “Instrucción [...]”, f. 2r, artículos 3.

56 AGI, Guatemala, 57, “Comisión [...]”, f. lv. Véase también la provisión de 1700 (AGI, Escribanía, 369B, "Testimonio [...]", ff. 66v-67r) y la instrucción de 1767 (AGI, Guatemala, 560, "Instrucción [...]", ff. 2r-2v, artículos 3 y 6).

${ }^{57}$ AGCA, Chiapas, A3, leg. 357, exp. 4547, ff. 33v-34r. [Padrón de tributarios de la parcialidad de doña Magdalena de Mazariegos en el pueblo de Palenque], Palenque, 10 de marzo de 1663.

${ }^{58}$ AGCA, Chiapas, A3, leg. 300, exp. 4045, f. 3r.

${ }^{59}$ Es probable que en la Nueva España a fines del siglo XVI o principios del XVII se comenzaran a revisar los libros parroquiales al realizar el padrón de tributarios (Miranda, 1952: 326-329). Para la provincia de Chiapas, la obligación de revisar los libros parroquiales no se encuentra en la provisión de 1581, pero sí en la de 1700 y en la instrucción de 1767: AGI, Escribanía, 369B, "Testimonio [...]", f. 67v; AGI, Guatemala, 560, "Instrucción [...]", ff. 2r-2v, artículos 5 y 6. La evidencia documental más antigua que hemos encontrado es el padrón de una parcialidad de Palenque: AGCA, Chiapas, A3, leg. 357, exp. 4.547, ff. 33v-34r. [Padrón de tributarios de la parcialidad de doña Magdalena de Mazariegos en el pueblo de Palenque]. Palenque, 10 de marzo de 1663. Sobre el padrón de Chiapa de 1759 trataremos con más detalle en la tercera parte de este trabajo.

${ }^{60}$ AGI, Escribanía, 369B, "Testimonio [...]”, ff. 67r-67v.

${ }^{61}$ AGCA, Chiapas, A3, leg. 358, exp. 4599, ff. 2r-7r y $10 \mathrm{r}-13 \mathrm{v}$.
${ }^{62}$ El padrón siguiente de Ixtacomitán fue realizado en 1747: AGCA, Chiapas, A3, leg. 299, exp. 4043, ff. 65r-66v.

${ }^{63}$ AHDSC, fondo parroquial, caja 1, libro 2, ff. 30r-98v. [Libro de bautizos de Acala], 1789-1802. Véase también el cuadroldeObara-Saeki (2010: 48). Desgraciadamente no hemos podido localizar los registros de bautizos realizados entre 1803 y 1816 en el curato de Acala.

${ }^{64}$ AGCA, Chiapas, A3, leg. 308, exp. 4175.

${ }^{65}$ AGCA, Chiapas, A3, leg. 300, exp. 4045.

${ }^{66}$ En este padrón se considera "huérfanos" a los niños cuyos padres hayan fallecido, independientemente de que sus madres estén vivas o no.

${ }^{67}$ Véase la nota 66.

${ }^{68}$ En el distrito de la Audiencia de Guatemala, cuando tributarios de un pueblo, ya fueran hombres o mujeres, se casaban con hombres y mujeres forasteros, se consideraba que la calidad de las madres se transmitía a sus hijos. Lo hemos mostrado en un trabajo anterior (Obara-Saeki, 2010).

${ }^{69}$ En este cálculo no hemos incluido a los indios caciques ni a los forasteros residentes en el pueblo de Chiapa mencionados en las categorías II y V. Tampoco a los indios de Chiapa que vivían fuera del pueblo ni a los indios huidos.

${ }^{70}$ En el Archivo General de Centro América (AGCA, Chiapas, A3) hemos consultado los siguientes padrones de tributarios: cuatro de la década de 1700 (leg. 357, exp. 4571; leg. 358, exp. 4599, ff. 2r-7r y 10r-13v; y exp. 461l); dos de la de 1710 (leg. 358, exps. 4604 y 4613); siete de la de 1720 (leg. 358, exps. 4625-4629, 4631 y 4632); nueve de la de 1730 (leg. 359, exps. 4640, 4645-4650, 4653 y 4655); nueve de la de 1740 (leg. 298, exp. 4022; leg. 359, exp. 4644; leg. 360, exps. 4656, 4658, 46614663, 4665; leg. 361, exp. 4678); once de la de 1750 (leg. 300, exp. 4045; leg. 361, exps. 4668-4672, 4676, 4677 y 4679-4681); uno de 1764 (leg. 361, exp. 4.686); cuatro realizados en 1795 y 1796 (AGCA, Chiapas, A3, leg. 305, exp. 4.112 [2], ff. 49r-63v; exp. 4112 [3], ff. 59r-79r; exp. 4112 [4]-[7]); y 71 padrones realizados en 1816 y 1817 
(AGCA, Chiapas, A3, leg. 307, exps. 4147 y 4150-4167; leg. 308, exps. 4168 y 4172-4177; leg. 309, exps. 41784194; leg. 310, exps. 4195-4200; leg. 311, exps. 42014208). Aparte, hemos investigado un padrón del pueblo de Chiapa realizado en 1768 en el Archivo Histórico de Chiapas (AHC, fondo reservado).

${ }^{71}$ AGCA, Chiapas, A3, leg. 357, exp. 4547, ff. 33v-34r.

${ }^{72}$ Gasco, "Archivo General de Indias...”, p. 282.

${ }^{73}$ AGCA, Chiapas, A3, leg. 357, exp. 4547, ff. 33v-34r.

${ }^{74}$ Véase la nota 70.

${ }^{75}$ Véase la nota 70.

${ }^{76}$ Recopilación de Indias..., vol. 2, libro 6, título 5, ley 23, f. 212r.

77 AGI, Guatemala, 560, "Instrucción [...]".

${ }^{78}$ Se mandó registrar en el inicio del padrón el número de bautizos, matrimonios y entierros celebrados desde la realización del último padrón; y en el fin del padrón, la suma de personas clasificadas en cada categoría. Por otra parte, se mandó apuntar al margen de cada partida el número de personas de cada categoría con el fin de facilitar la suma final.

${ }^{79}$ Véase la nota 70.

\section{Bibliografía}

Arias de Blois, Jorge (1994), “Evolución demográfica hasta 1700", en Luján Muñoz, Jorge y Ernesto Chinchilla Aguilar (eds.), Historia general de Guatemala, vol. 2, Guatemala: Asociación de Amigos del País; y Fundación para la Cultura y el Desarrollo, pp. 313326.

Borah, Woodrow y Sherburne F. Cook (1960), The population of central Mexico in 1548: an analysis of the Suma de visitas de pueblos, Berkeley: University of California Press.

Calvo, Thomas (1973), Acatzingo: Demografía de una parroquia mexicana, México: Instituto Nacional de Antropología e Historia.

Carmack, Robert M. (1981), "Patrones sociales y demográficos en un censo del siglo XVIII en
Momostenango. Guatemala”, en Mesoamérica, año 1, núm. 2, junio de 1981, pp. 42-63.

Cook, Sherburne F. y Woodrow Borah, Ensayos sobre historia de la población: México y el Caribe, 2 vol, México: Siglo XXI, 1998 [1971 y 1974].

Feria, Pedro de (1980), "Carta de fray Pedro de Feria, obispo de Chiapas, al rey don Felipe II, remitiéndole un memorial de lo que en aquella provincia pasaba. Chiapa, 26 de enero de 1579", en Cartas de Indias, México: Secretaría de Hacienda y Crédito Público; y Miguel Ángel Porrúa, [1877], pp. 451-459.

Gasco, Janine (1990),"Archivo General de Indias, Escribanía de Cámara, legajo 331-A, ff. 1537-1558v", en Mesoamérica, año 1l, cuaderno 20, diciembre de 1990, pp. 275-297.

Gerhard, Peter (1991), La frontera sureste de la Nueva España, México: Universidad Nacional Autónoma de México, [1979].

Gibson, Charles (1984), Los aztecas bajo el dominio español (1519-1810), México: Siglo XXI, [1964].

Klein, Herbert S. (1986), "Familia y fertilidad en Amatenango, Chiapas, 1785-1816", en Historia Mexicana, 36(2), pp. 273-286.

Lenkersdorf, Gudrun (1993), Génesis histórica de Chiapas, 1522-1532: El conflicto entre Portocarrero y Mazariegos, México: Universidad Nacional Autónoma de México,

Lovell, W. George (1990), Conquista y cambio cultural: La sierra de los Cuchumatanes de Guatemala 1500-1821, Antigua Guatemala: Centro de Investigaciones Regionales de Mesoamérica.

Lovell, W. George y Christopher H. Lutz (2000), Demografía e imperio: Guía para la historia de la población de la América Central española, 1500-1821, Guatemala: Universidad de San Carlos.

Lutz, Christopher H. (1982), Historia sociodemográfica de Santiago de Guatemala, 1541-1773, Guatemala: Centro de Investigaciones Regionales de Mesoamérica.

Lutz, Christopher H. (1994), "Evolución demográfica de la población no indígena”, en Luján Muñoz, Jorge y 
Ernesto Chinchilla Aguilar (eds.), Historia general de Guatemala, 2 vol, Guatemala: Asociación de Amigos del País; y Fundación para la Cultura y el Desarrollo, pp. 249-258.

Miranda, José (1952), El tributo indígena en la Nueva España durante el siglo XVI, México: El Colegio de México.

Morin, Claude (1972), "Los libros parroquiales como fuente para la historia demográfica y social novohispana", en Historia Mexicana, 21(3), pp. 389 418.

Morin, Claude (1973), Santa Inés Zacatelco (1646-1812): contribución a la demografía histórica del México colonial, México: Instituto Nacional de Antropología e Historia.

Obara-Saeki, Tadashi (2010), Ladinización sin mestizaje: historia demográfica del ârea Chiapaneca, 1748-1813, Tuxtla Gutiérrez: Consejo Estatal para las Culturas y las Artes de Chiapas; H. Ayuntamiento Constitucional de Chiapa de Corzo.

Pastor, Rodolfo (1988), Historia de Centroamérica, México: El Colegio de México.

Pescador, Juan Javier (1992), De bautizos a fieles difuntos: familia y mentalidad en una parroquia urbana, Santa Catarina de México, 1586-1820, México: El Colegio de México.
Rabell, Cecilia (1990), La población novohispana a la luz de los registros parroquiales: avances y perspectivas de investigación, México: Universidad Nacional Autónoma de México. Recopilación de leyes de los reynos de las Indias: Mandadas imprimir y publicar por la magestad católica del rey, don Carlos II, nuestro señor, (1973) 2 vol, Madrid: Ediciones Cultura Hispánica, [1681].

Robichaux, David (2001), "Uso del método de la reconstitución de familias en las poblaciones indígenas", en Papeles de Población, núm. 28, abril-junio de 2001, pp. 99-129.

Sánchez-Albornoz, Nicolás (1994), La población de América latina: Desde los tiempos precolombinos al año 2025, Madrid: Alianza Editorial, [1973].

Viqueira, Juan Pedro (1997), Indios rebeldes e idólatras. Dos ensayos históricos sobre la rebelión india de Cancuc, Chiapas, acaecida en el año de 1712, México: Centro de Investigaciones y Estudios Superiores en Antropología Social.

Ximénez, Francisco (1999), Historia de la provincia de San Vicente de Chiapa y Guatemala de la orden de predicadores, 5 vols., Tuxtla Gutiérrez: Consejo Estatal para la Cultura y las Artes de Chiapas.

Zavala, Silvio A. (1973), La encomienda indiana, México: Editorial Porrúa, [1935]. 